Macedonian Pharmaceutical Bulletin, 66 (Suppl 1) 39 - 40 (2020)

Online ISSN 1857 - 8969

UDC: 616.61-008.64-083.2

DOI: 10.33320/maced.pharm.bull.2020.66.03.019

Short communication

\title{
Nutritional management of chronic kidney disease - a case report
}

\author{
Dafina Boshkoska ${ }^{1}$, Bojana Janeku ${ }^{1}$, Elena Karabeleski ${ }^{1}$, Menka Andreska ${ }^{1}$, \\ Suzana Atanasovikj ${ }^{1}$, Dragana Mladenovska ${ }^{1}$, Jasminka Patcheva ${ }^{2}$, Kristina \\ Mladenovska ${ }^{1}$, Lidija Petrushevska-Tozi ${ }^{1}$, Tanja Petreska Ivanovska ${ }^{1}$, \\ Aleksandra Kapedanovska Nestorovska ${ }^{1}$ \\ ${ }^{1}$ Faculty of Pharmacy, Ss. Cyril and Methodius University, Mother Theresa 47, \\ 1000 Skopje, N. Macedonia \\ ${ }^{2}$ Pharmaceutical Chamber of Macedonia, $50^{\text {th }}$ Division 34, 1000 Skopje, N. Macedonia
}

\section{Introduction}

Chronic kidney disease (CKD) is typically a progressive syndrome in which kidneys lose their ability to filter blood, concentrate urine, excrete waste and maintain electrolyte balance. CKD is an important public health issue that consumes major global health care resources. The worldwide prevalence of renal dysfunction is estimated to be between $11 \%$ and $13 \%$ (Hill et al., 2016).

Dietetic-nutritional therapy (DNT) is an important component of conservative treatment of patients suffering from $\mathrm{CKD}$, aiming to maintain an optimal nutritional status, prevent and/or correct signs, symptoms and complications of CKD and to delay starting of dialysis. Modulation of protein intake, adequacy of caloric intake, and control of sodium and potassium levels as well as reduction of phosphorus intake is the essential points of DNT (Cupisti et al., 2018).

In this paper, a case of patient with CKD, stadium 5 is presented, with an aim to emphasize the importance of setting nutritive diagnosis in these patients and establishing a plan for nutritive intervention. Criteria for nutritive monitoring and evaluation of the outcomes associated with each recommended nutritive intervention are also given.

\section{Case presentation}

A 26-years old, female patient $(77 \mathrm{~kg}, 152 \mathrm{~cm}$ height, BMI $33.33 \mathrm{~kg} / \mathrm{m}^{2}$ ) was hospitalized at the Clinic of Nephrology, with symptoms of anorexia, edema, and difficulties in breathing, pruritus and inability to urinate. Previous medical history included renal insufficiency, hypertension and diabetes mellitus type 2 . The patient was diagnosed with CKD, stadium 5 and was about to start hemodialysis. CKD was caused by untreated diabetes mellitus and was presented by damages of glomerular wall, increased perfusion, protein loss, edema and metabolic acidosis, uremia, azotemia, hyperphosphatemia, hyperkalemia, oliguria and hypertension.

The patient had poor appetite, but had $4 \mathrm{~kg}$ recent weight gain. In the past 24 hours, she had toast and cola for breakfast, ham and cheese sandwich and ice tea for lunch and spaghetti portion and ice tea for dinner.

\footnotetext{
*dafinaboskoska@yahoo.com
} 
Actual pharmacotherapy included captopril, calcitriol, erythropoietin, vitamin and mineral supplements and glucophage.

\section{Discussion}

The nutritive intervention in this patient should include prevention of malnutrition, minimization of uremia, decreasing of complications (cardiovascular diseases, anemia and secondary hyperparathyroidism), as well as normalization of blood pressure. In addition, in patients with CKD (stadium 4-5), a diet with non-monitored intake of energy, protein, sodium and phosphate hastens and exacerbate clinical and metabolic alterations related to advanced CKD. This can reduce the effectiveness of drug therapy or require an increase in dosage, while DNT must be managed according to the stages and criteria of any other drug therapy (Cupisti et al., 2018). Therefore, the patient's diet should be rich in proteins and the intake of potassium, sodium, phosphates and water should be strictly regulated. Consumption of food with appropriate energy value is very important for balancing the optimal nutritive status. Fat intake should be also controlled. If the patient is on dialysis, foods rich in potassium, sodium and water should be limited. There should be restriction on consumption of fruits, vegetables, nuts and seeds, chocolates and milk products.

Hence, the recommendations for DNT in the patient include: consumption of food poor in potassium (apple, apple juice, canned apricots, berries, grapefruit, tangerine, peaches, pears, pineapple, plums, watermelon (limit on 1 piece), asparagus, beans, cabbage, carrots (boiled), cauliflower, celery, cucumber, eggplant, mushrooms, onion, parsley, paprika, rice, bread, sweets without nuts and chocolate, potassium from the fresh vegetables is removed by blanching); food poor in sodium (fresh and frosty meat, eggs, milk products (only once a day), fresh and frozen vegetables without added salt, vegetable olive and canola oil, garlic, onion, black pepper, lemon, homemade soups and canned food without added salt); decreased intake of liquids; intake of less salted food; administration of medicines with the liquids from the meal; taking liquids only when thirsty (for moisturizing the mouth, bonbons without sugar to be used, ice cream, sorbet and yogurt are considered liquids); avoiding food rich in phosphorus (chocolate, beer, cocoa, cola drinks, cheese, milk, yogurt, ice cream, liver, sardines, bean, pea, soya, lentils, wholegrain cereals and nuts).

As an example, the daily menu of the patient could include: $1 / 2$ glass apple juice, $100 \mathrm{ml}$ full fat milk, 1 muffin, $220 \mathrm{ml}$ filter café and rice cereals for breakfast; turkey sandwich (56 g meat, 2 slices white bread, 1 tablespoon mayonnaise, 2 leaves lettuce), $1 / 2$ glass pomegranate juice, $1 / 2$ glass canned peaches and 2 small graham crackers for lunch; and $56 \mathrm{~g}$ roasted pork, $1 / 2$ glass white rice, 1 glass pineapple and 1 small piece of cake for dinner.

\section{Conclusion}

A person may prevent or delay some health problems from CKD by eating recommended foods and avoiding foods high in sodium, potassium, and phosphorus. Proper information about calories, fats, proteins and fluids in allowed food products is important for a person with advanced CKD. Foods rich in proteins such as meat and dairy products break down into waste products that are removed from the blood by healthy kidneys. As CKD progresses, nutritional habits must change. A health care provider, including dietitian, may recommend a patient with reduced kidney function to choose foods very carefully.

\section{References}

Cupisti, A., Brunori, G., Di Iorio, B.R., D'Alessandro, C., Pasticci, F., Cosola, C., Bellizzi, V., Bolasco, P., Capitanini, A., Fantuzz, A.L., Gennari, A., Piccoli, G.B., Quintaliani, G., Salomone, M., Sandrini, M., Santoro, D., Babini, P., Fiaccador, E., Gambaro, G., Garibott, G., Gregorini, M., Mandreoli, M., Minutolo, R., Cancarini, G., Conte, G., Locatelli, F., Gesualdo, L., 2018. Nutritional treatment of advanced CKD: twenty consensus statements. J. Nephrol. 31(4), 457473.

Hill, N.R, Fatoba S.T, Oke J.L, Hirst, J.A., O'Callaghan, C.A., Lasserson, D.S., Hobbs, F.D.R., 2016. Global prevalence of chronic kidney disease - A systematic review and meta-analysis. PLoS ONE 11(7), e0158765.

Maced. Pharm. Bull. 66 (Suppl 1) 39 - 40 (2020) 